\title{
Fuzzy Eoq Model for Deteriorating Items with Exponential Membership Function
}

\author{
H.P. UMAP* \\ Department of Statistics, Yashavantrao Chavan Institute of Science, Satara (M.S.) \\ *Corresponding author: hemant_umap@yahoo.com \\ Received June 03, 2014; Revised July 03, 2014; Accepted July 07, 2014
}

\begin{abstract}
In this Paper a multi item EOQ model with stock dependent demand for deteriorating items is considered in fuzzy environment. Inventory costs such as holding cost and setup cost have been represented by exponential membership function and profit, deteriorating rate and total investment constraint are represented by linear membership functions. The model has been solved by fuzzy non-linear programming (FNLP) method. Results have been presented along with those of corresponding crisp model and a sensitivity analysis.
\end{abstract}

Keywords: fuzzy inventory, crisp model, non-linear membership function

Cite This Article: H.P. UMAP, "Fuzzy Eoq Model for Deteriorating Items with Exponential Membership Function." American Journal of Applied Mathematics and Statistics, vol. 2, no. 4 (2014): 203-206. doi: 10.12691/ajams-2-4-4.

\section{Introduction}

Now a classical EOQ is an old-age problem several researchers worked on the EOQ model by changing the parameters and variables of the model. All these models are developed in crisp environment. This literature is available in various reference journals and survey papers

Generally Demand rate is considered to be constant, time dependent, ramp type and selling price dependent. However in present competitive market stock-dependent demand plays an important role in increase its demand.

Deterioration is one of the important factors in inventory system. Some items like food grains, vegetables, milk, eggs etc. deteriorate during their storage time and retailer suffers loss. In an inventory system available storage space, budget, number of orders etc. are always limited hence multi-item classical inventory models under these constraints have great importance.

In realistic situation all the parameters, variables and resources are always considered as constant. But their value, instead of being at a fixed level varies within a range.

Due to this vagueness and uncertainty of inventory parameters, the fuzzy set theory is more appropriate to formulate inventory model. In fuzzy decision-making process first Bellman and Zadeh [1] introduced fuzzy set theory. Tanaka et. al. [6] used the concept of fuzzy sets to decision problems and Zimmerman [7] showed the classical algorithms could be used to solve fuzzy linear programming problems.

Normally both linear and non-linear shapes for the membership functions of the fuzzy objective and constraints are proposed. In this area Mandal and Maiti [5] and Mandal, Roy and Maiti [4] solved the classical EOQ model in a fuzzy environment with fuzzy objective, fuzzy inventory costs with constraints like storage area, total budget etc., by non-linear programming method using linear as well as several types of non-linear membership functions for inventory parameters.

In this paper a multi item EOQ model with stock dependent demand for deteriorating items is considered in fuzzy environment. Here inventory costs such as holding cost and setup cost have been represented by exponential membership functions and profit, deteriorating rate and total investment constraint are represented by linear membership functions. The model has been solved by fuzzy non-linear programming (FNLP) method. Results have been presented along with those of corresponding crisp model and a sensitivity analysis.

\section{Assumptions}

1. The scheduling period is constant and no lead-time.

2. Replenishment rate is infinite.

3. Selling price is Known and constant.

4. Demand rate is stock dependent.

5. Shortages are not allowed.

6. Deteriorating rate is age specific failure rate.

\section{Notations}

$\mathrm{T}_{\mathrm{i}}$ : Time period for each cycle for the $\mathrm{i}^{\text {th }}$ item.

$\mathrm{R}_{\mathrm{i}}$ : Demand rate per unit time of $\mathrm{i}^{\text {th }}$ item; $\left[\mathrm{R}_{\mathrm{i}}=\mathrm{a}_{\mathrm{i}}+\mathrm{b}_{\mathrm{i}} \mathrm{q}_{\mathrm{i}}\right]$.

$\theta_{\mathrm{i}}$ : Deterioration rate of $\mathrm{i}^{\text {th }}$ item.

$\mathrm{Q}_{\mathrm{i}}\left(\mathrm{t}\right.$ : Inventory level at time $\mathrm{t}$ of $\mathrm{i}^{\text {th }}$ item.

$\mathrm{C}_{\mathrm{H}}$ : Total Holding cost.

$\mathrm{C}_{1 \mathrm{i}}$ : Holding cost per unit of $\mathrm{i}^{\text {th }}$ item.

$\mathrm{C}_{3 \mathrm{i}}$ : Set up cost for $\mathrm{i}^{\text {th }}$ item.

$\mathrm{S}_{\mathrm{di}}$ : Total deteriorating units of $\mathrm{i}^{\text {th }}$ item.

$\mathrm{P}_{\mathrm{i} \text { : }}$ Selling price per unit of $\mathrm{i}^{\text {th }}$ item. 
$\mathrm{Q}_{\mathrm{i}}$ : Initial stock level of $\mathrm{i}^{\text {th }}$ item.

PF(Qi): Total profit of $i^{\text {th }}$ item.

$\mathrm{n}$ : Number of items.

(wavy bar $(\sim)$ represents the fuzzification of the parameters)

\section{Mathematical Formulation}

\subsection{Crisp Model}

As $\mathrm{Q}_{\mathrm{i}}(\mathrm{t})$ is the inventory level at time $\mathrm{t}$ of the $\mathrm{i}^{\mathrm{th}}$ item, then the differential equation describing the state of inventory is given by

$$
\begin{array}{r}
\frac{\mathrm{d}}{\mathrm{dt}} \mathrm{Q}_{\mathrm{i}}(\mathrm{t})+\theta_{\mathrm{i}} \mathrm{Q}_{\mathrm{i}}(\mathrm{t})=-\left(\mathrm{a}_{\mathrm{i}}+\mathrm{b}_{\mathrm{i}} \mathrm{Q}_{\mathrm{i}}(\mathrm{t})\right) \\
0 \leq \mathrm{t} \leq \mathrm{T}_{\mathrm{i}}
\end{array}
$$

solving the above differential equation using boundary condition $\mathrm{Q}_{\mathrm{i}}(\mathrm{t})=\mathrm{Q}_{\mathrm{i}}$ at $\mathrm{t}=\mathrm{o}$, we get

$$
Q_{i}(t)=-\frac{a_{i}}{\left(\theta_{i}+b_{i}\right)}+\left[Q_{i}+\frac{a_{i}}{\left(\theta_{i}+b_{i}\right)}\right] e^{-\left(\theta_{i}+b_{i}\right) t}
$$

and using boundary condition $\mathrm{Q}_{\mathrm{i}}(\mathrm{t})=0$ at $\mathrm{t}=\mathrm{Ti}$

$$
\therefore \mathrm{T}_{\mathrm{i}}=\frac{1}{\left(\theta_{\mathrm{i}}+\mathrm{b}_{\mathrm{i}}\right)} \log \left\{1+\frac{\left(\theta_{\mathrm{i}}+\mathrm{b}_{\mathrm{i}}\right) \mathrm{Q}_{\mathrm{i}}}{\mathrm{a}_{\mathrm{i}}}\right\}
$$

The holding cost of $\mathrm{i}^{\text {th }}$ item in each cycle is

$$
\mathrm{C}_{\mathrm{H}}=\mathrm{C}_{1 \mathrm{i}} \mathrm{G}_{\mathrm{i}}\left(\mathrm{Q}_{\mathrm{i}}\right)
$$

where,

$$
\begin{aligned}
& G_{i}\left(Q_{i}\right)=\int_{0}^{Q_{i}} \frac{q_{i} d q_{i}}{a_{i}+\left(\theta_{i}+b_{i}\right) q_{i}} \\
& =\frac{Q_{i}}{\left(\theta_{i}+b_{i}\right)}+\frac{a_{i}}{\left(\theta_{i}+b_{i}\right)^{2}} \log \left\{1+\frac{\left(\theta_{i}+b_{i}\right) Q_{i}}{a_{i}}\right\}
\end{aligned}
$$

By neglecting the higher power terms, we get

$$
\mathrm{G}_{\mathrm{i}}\left(\mathrm{Q}_{\mathrm{i}}\right)=\frac{\mathrm{Q}_{\mathrm{i}}^{2}}{2 \mathrm{a}_{\mathrm{i}}}\left\{1-2 \frac{\left(\theta_{\mathrm{i}}+\mathrm{b}_{\mathrm{i}}\right) \mathrm{Q}_{\mathrm{i}}}{3 \mathrm{a}_{\mathrm{i}}}\right\}
$$

The total number of deteriorating units of the $\mathrm{i}^{\text {th }}$ item is

$$
S_{d i}\left(Q_{i}\right)=\theta_{i} G_{i}\left(Q_{i}\right)
$$

The net revenue for the $i^{\text {th }}$ item is

$$
\begin{aligned}
& N\left(Q_{i}\right)=\left(P_{i}-C_{i}\right) Q_{i}-P_{i} \cdot S_{d i}\left(Q_{i}\right) \\
& N\left(Q_{i}\right)=\left(P_{i}-C_{i}\right) Q_{i}-P_{i} \theta_{i} \cdot G_{i}\left(Q_{i}\right)
\end{aligned}
$$

The profit of $\mathrm{i}^{\text {th }}$ item is

$$
\begin{gathered}
P F\left(Q_{i}\right)=N\left(Q_{i}\right)-C_{1 i} G_{i}\left(Q_{i}\right)-C_{3 i}, i=1,2,---n . \\
P F\left(Q_{i}\right)=\left(P_{i}-C_{i}\right) Q_{i}-P_{i} \theta_{i} \cdot G_{i}\left(Q_{i}\right) \\
-C_{1 i} G_{i}\left(Q_{i}\right)-C_{3 i}, \quad i=1,2,---n . \\
P F\left(Q_{i}\right)=\left(P_{i}-C_{i}\right) Q_{i}-\left(C_{1 i}+P_{i} \theta_{i}\right) G_{i}\left(Q_{i}\right)-C_{3 i}, \\
i=1,2,---n .
\end{gathered}
$$

Hence the problem is

$$
\operatorname{Max} P F=\sum_{i=1}^{n}\left[\begin{array}{l}
\left(P_{i}-C_{i}\right) Q_{i}-\left(C_{1 i}\right. \\
\left.+P_{i} \theta_{i}\right) G_{i}\left(Q_{i}\right)-C_{3 i}
\end{array}\right]
$$

subject to

$$
\begin{gathered}
\sum_{\mathrm{i}=1}^{\mathrm{n}} \mathrm{C}_{\mathrm{i}} \mathrm{Q}_{\mathrm{i}} \leq \mathrm{B} \\
\mathrm{Q}_{\mathrm{i}} \geq 0, \quad \mathrm{i}=1,2,3,---, \mathrm{n}
\end{gathered}
$$

\subsection{Fuzzy Model}

When above profit, costs, deteriorating rate and total budget become fuzzy, the said crisp model is transform to

Max $P F=\sum_{i=1}^{n}\left[\left(P_{i}-C_{i}\right) Q_{i}-\left(\tilde{C}_{1 i}+P_{i} \tilde{\theta}_{i}\right) G_{i}\left(Q_{i}\right)-\tilde{C}_{3 i}\right]$

subject to

$$
\begin{gathered}
\sum_{\mathrm{i}=1}^{\mathrm{n}} \mathrm{C}_{\mathrm{i}} \mathrm{Q}_{\mathrm{i}} \leq \tilde{\mathrm{B}} \\
\mathrm{Q}_{\mathrm{i}} \geq 0, \quad \mathrm{i}=1,2,3,---, \mathrm{n}
\end{gathered}
$$

\section{Mathematical Analysis}

A crisp non-linear programming problem may be defined as follows

$$
\begin{aligned}
& \text { Max } g_{0}\left(x, c_{0}\right) \\
& \text { subject to } \\
& \begin{array}{c}
g_{r}\left(x, c_{r}\right) \leq b_{r} \quad, \quad r=1,2,---, m . \\
x \geq 0
\end{array}
\end{aligned}
$$

where $X=\left(X_{1}, X_{2},---, X_{n}\right)^{T}$ is a variable vector $\mathrm{g}_{0}, \mathrm{~g}_{\mathrm{r}}$ 's are algebraic expressions in $x$ with coefficients $\quad C_{0}=\left(C_{01}, C_{02},---, C_{0 n}\right)^{T} \quad$ and $C_{r}=\left(C_{r 1}, C_{r 2},---, C_{r l}\right)^{T} \quad$ respectively. Introducing fuzziness in the crisp parameters, the above problem in fuzzy environment becomes

Mãx $g_{0}\left(x, \tilde{C}_{0}\right)$

subject to

$$
\begin{gathered}
\mathrm{g}_{\mathrm{r}}\left(\mathrm{x}, \tilde{\mathrm{C}}_{\mathrm{r}}\right) \leq \tilde{\mathrm{b}}_{\mathrm{r}} \quad, \quad \mathrm{r}=1,2,---, \mathrm{m} . \\
\mathrm{x} \geq 0
\end{gathered}
$$

In fuzzy set theory the fuzzy objective goal, coefficients and resources are defined by their membership functions, which may be linear and / or non-linear. According to Bellman and Zadeh [1] and following carlsson and korhnen [2] above problem is transform to

$$
\begin{aligned}
& \text { Max } \alpha \text { subject to } \\
& \mathrm{g}_{\mathrm{o}}\left(\mathrm{x}, \mu \mathrm{C} 0^{-1}(\alpha)\right) \leq \mu \mathrm{O}^{-1}(\alpha) \\
& \mathrm{g}_{r}\left(\mathrm{x}, \mu \mathrm{Cr}{ }^{-1}(\alpha)\right) \geq \mu \mathrm{r}^{-1}(\alpha), \mathrm{r}=1,2,---\mathrm{m} \\
& \mathrm{x} \geq 0, \alpha \in[0,1] \\
& \text { where } \mu \mathrm{Cr}^{-1}=\left\{\mu \mathrm{C}^{-1} \mu \mathrm{C} 2^{-1}--\mu_{\mathrm{Ck}}^{-1}\right\}
\end{aligned}
$$


Fuzzy goal, costs, deteriorating rate and total budget are representing by combinations of linear and non-linear membership functions:

Here Exponential membership function is considered to represent the fuzzy costs and fuzzy goal, deteriorating rate and total budget are represented by linear membership function.

\section{Case I) Linear Membership Function}

We assume continuous linear membership functions to be non-decreasing for inventory costs and non-increasing for fuzzy goal and constraints and these are

$$
\mu_{0}\left(g_{0}(x)\right)=\left\{\begin{array}{l}
1-\left(\frac{g_{0}(x)-b_{0}}{\mathrm{P}_{0}}\right) ; b_{0} \leq g_{0}(x) \leq b_{0}+\mathrm{P}_{0} \\
0 \quad ; \mathrm{b}_{0}(\mathrm{x})>\mathrm{b}_{0}+\mathrm{P}_{0}
\end{array}\right.
$$

and

$$
\mu_{\mathrm{Coi}}=\left\{\begin{array}{l}
1-\left(\frac{\mathrm{A}_{\mathrm{oj}}-\mathrm{u}}{\mathrm{P}_{\mathrm{oj}}}\right) ; \mathrm{A}_{\mathrm{oj}} \\
0 \quad, \mathrm{~A} \leq \mathrm{A}_{\mathrm{oj}}-\mathrm{P}_{\mathrm{oj}}-\mathrm{u} \leq \mathrm{A}_{\mathrm{oj}}
\end{array}\right.
$$

Here $\mathrm{p}_{0}$ and $\mathrm{P}_{0}$ 's are the maximally acceptable violation of the aspiration levels $b_{0}$ and $A_{0 j}$ 's.

Case II) Non - linear Membership

\section{Function}

\subsection{Exponential Membership Function}

In this case

$\mu_{\mathrm{Ci}}(\mathrm{u})= \begin{cases}1 & ; \mathrm{u}>\mathrm{C}_{\mathrm{i}} \\ \left(\frac{\mathrm{q}^{\mathrm{t}\left(\mathrm{C}_{\mathrm{i}}-\mathrm{u}\right) / \mathrm{PC}_{\mathrm{i}-\mathrm{q}} \mathrm{t}}}{\left(1-\mathrm{q}^{\mathrm{t}}\right)}\right) ; \mathrm{C}_{\mathrm{i}}-\mathrm{PC}_{\mathrm{i}} \leq \mathrm{u} \leq \mathrm{C}_{\mathrm{i}} \\ & ; \mathrm{u}<\mathrm{C}_{\mathrm{i}}-\mathrm{PC}_{\mathrm{i}}\end{cases}$

where $0<\mathrm{q}<1, \mathrm{t}>0, \mathrm{i}=1,3$. It's pictorial representation is

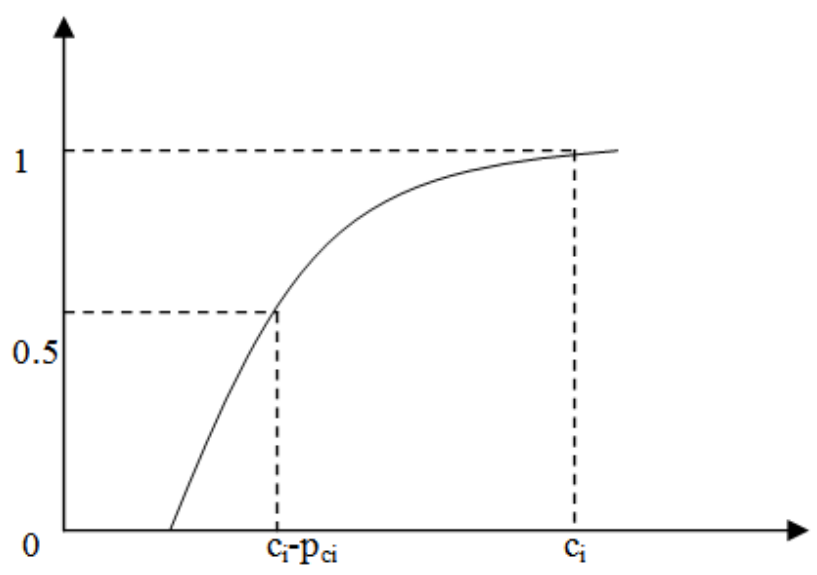

Figure. Exponential membership function of $\tilde{C}_{i}$

Let $\mathrm{q}=0.5$ and $\mathrm{t}=1$ then

$$
\mu_{c i}^{-1}(\alpha)=C i-P_{c i} \log _{0.5}(0.5+0.5 \alpha)
$$

Model: Fuzzy costs represented by exponential membership function and fuzzy goal, deteriorating rate and total budget are represented by linear membership function

Let

$$
\begin{aligned}
& \mu_{c 1 i}^{-1}(\alpha)=c 1 i-P_{c 1 i} \log _{0.5}(0.5+0.5 \alpha) \\
& \mu_{c 3 i}^{-1}(\alpha)=c 3 i-P_{c 3 i} \log _{0.5}(0.5+0.5 \alpha) \\
& \mu_{\theta \mathrm{i}}^{-1}(\alpha)=\theta \mathrm{i}+\mathrm{P}_{\theta \mathrm{i}}(1-\alpha) \\
& \mu_{P F}^{-1}(\alpha)=P F_{o}-P_{P F}(1-\alpha) \\
& \mu_{B}^{-1}(\alpha)=B+P_{B}(1-\alpha)
\end{aligned}
$$

Here $\mathrm{P}_{\mathrm{PF}}, \mathrm{P}_{\theta \mathrm{i}}$ are the maximum acceptable violation of the aspiration levels $\mathrm{PF}_{\mathrm{o}}$ and $\mathrm{B}$.

Then the fuzzy model reduces to crisp model as:

$\operatorname{Max} \alpha$

subject to

$$
\begin{aligned}
& \mathrm{PF}\left(\mathrm{Q}_{\mathrm{i}}, \alpha\right) \geq \mathrm{PF}_{\mathrm{O}}-\mathrm{P}_{\mathrm{PF}}(1-\alpha) \\
& \sum_{\mathrm{i}=1}^{\mathrm{n}} \mathrm{C}_{\mathrm{i}} \mathrm{Q}_{\mathrm{i}} \leq \mathrm{B}+\mathrm{P}_{\mathrm{B}}(1-\alpha) \\
& \mathrm{Q}_{\mathrm{i}} \geq 0, \alpha \in[0,1]
\end{aligned}
$$

Where Qi >0 (i=1,2,---n) are decision variables and

$$
\begin{aligned}
& \operatorname{PF}\left(Q_{\mathrm{i}}, \alpha\right)= \sum_{\mathrm{i}=1}^{\mathrm{n}}\left[\left(\mathrm{P}_{\mathrm{i}}-\mathrm{C}_{\mathrm{i}}\right) \mathrm{Q}_{\mathrm{i}}-\left[\left(\mathrm{C}_{1 \mathrm{i}}-\mathrm{P}_{\mathrm{c} 1 \mathrm{i}} \log _{0.5}(0.5+0.5 \alpha)\right)+\right.\right. \\
& \mathrm{P}_{\mathrm{i}}\left(\theta_{\mathrm{i}}+\mathrm{P}_{\theta \mathrm{i}}(1-\alpha)\right)\left\{\frac{\mathrm{Q}_{\mathrm{i}}^{2}}{2 \mathrm{a}_{\mathrm{i}}}\left[1-\frac{2\left[\left(\theta_{\mathrm{i}}+\mathrm{P}_{\theta \mathrm{i}}(1-\alpha)\right)+\mathrm{b}_{\mathrm{i}}\right]}{3 \mathrm{ai}}\right]\right\} \\
&-\left(\mathrm{C}_{3 \mathrm{i}}-\mathrm{P}_{\mathrm{c} 3 \mathrm{i}} \log _{0.5}(0.5+0.5 \alpha)\right]
\end{aligned}
$$

\section{Numerical Example}

For $\mathbf{N}=\mathbf{2}$

$\mathrm{P}_{1}=10, \mathrm{C}_{1}=7, \mathrm{a}_{1}=110, \mathrm{~b}_{1}=0.5, \theta_{1}=0.025, \mathrm{P}_{2}=10, \mathrm{C}_{2}=6.75$ $\mathrm{a}_{2}=100, \mathrm{~b}_{2}=0.5, \theta_{2}=0.03$,

$\mathrm{PF}_{\mathrm{o}}=500, \quad \mathrm{P}_{\mathrm{PF}}=50, \quad \mathrm{~B}=1800, \quad \mathrm{P}_{\mathrm{B}}=100, \quad \mathrm{P}_{\theta 1}=0.005$, $\mathrm{P}_{\theta 2}=0.005, \mathrm{C}_{11}=2, \mathrm{C}_{31}=65, \mathrm{C}_{12}=2.2, \mathrm{C}_{32}=50, \mathrm{P}_{\mathrm{C} 11}=0.05$, $\mathrm{P}_{\mathrm{C} 31}=10, \mathrm{P}_{\mathrm{C} 12}=0.05, \mathrm{P}_{\mathrm{C} 32}=10$

The optimum results are:

$\alpha=0.7256, Q_{1}=71.8234, Q_{2}=77.7292 \quad P F=257.6075$, $\mathrm{B}=1027.4379$.

From the above tables, it is observed that:

1. In Table 1.1, the optimum values are given for these fuzzy models with exponential membership function along with the crisp model. Here amount of profit varies from Rs. 193 to Rs. 299. As our permissible profit range is (210-260), only three crisp models profits fall within this range. Actually, if we make parametric studies on the crisp model with the different values of different parameters, results of some of those studies will coincide with the optimum values of fuzzy model. This laborious and time consuming parametric study can avoid by using fuzzy analysis. Depending on the experience or from past observed data, the exact form of membership functions for the variations of different inventory costs, objective and budget can be defined and then the optimum values are obtained for the appropriate fuzzy model. 
2. In Table 1.2 it is seen that $\boldsymbol{\alpha}$ increases but it never becomes one as it is expected. The values of decision variables (Qi's) become invariant but profit and budget decreases with the increase in tolerance of objective.

Table 1.1. Comparison Table

\begin{tabular}{|c|c|c|c|c|c|c|c|c|c|c|c|}
\hline \multicolumn{1}{|c|}{ Table 1.1. Comparison Table } \\
\hline Crisp & $\mathrm{C}_{11}$ & $\mathrm{C}_{12}$ & $\mathrm{C}_{31}$ & $\mathrm{C}_{32}$ & $\theta_{1}$ & $\theta_{2}$ & $\mathrm{~B}$ & $\mathrm{Q}_{1}$ & $\mathrm{Q}_{2}$ & $\mathrm{PF}$ \\
& 2.2 & 2.4 & 80 & 70 & 0.03 & 0.035 & 1000 & 58.67146 & 87.30367 & $205.8378 *$ & \\
& 2.1 & 2.3 & 80 & 80 & 0.035 & 0.035 & 1000 & 56.40799 & 89.65098 & $199.1940 *$ \\
& 2.4 & 2.4 & 65 & 60 & 0.02 & 0.03 & 1000 & 60.4744 & 85.8339 & 233.0279 \\
& 2 & 2.4 & 65 & 50 & 0.02 & 0.03 & 1000 & 45.9012 & 100.547 & 236.7420 \\
& 2 & 2.2 & 65 & 50 & 0.03 & 0.025 & 1100 & 65.6204 & 94.9122 & $275.0873 *$ \\
& 2 & 2.2 & 70 & 70 & 0.03 & 0.03 & 900 & 52.47932 & 78.91033 & 193.8238 \\
& 2 & 2.2 & 60 & 40 & 0.03 & 0.02 & 1100 & 50.5353 & 110.5561 & $298.0897 *$ \\
& 2 & 2.2 & 80 & 70 & 0.03 & 0.03 & 1000 & 60.6636 & 85.2377 & 213.0223 \\
Fuzzy & 2 & 2.2 & 65 & 50 & 0.025 & 0.03 & 1000 & 71.823 & 77.7292 & 257.6075 \\
\hline
\end{tabular}

* Not feasible with respect to the range considered for the objective goal (210 - 260)

\begin{tabular}{|c|c|c|c|c|c|}
\multicolumn{7}{|c|}{ Table 1.2. Effect oOf Variations in $\mathbf{P}_{\mathbf{P F}}$} \\
\hline $\mathrm{P}_{\mathrm{PF}}$ & $\alpha$ & $\mathrm{Q}_{1}$ & $\mathrm{Q}_{2}$ & PF & $\mathrm{B}$ \\
\hline 0 & 0.41 & 74.18 & 79.89 & 259.01 & 1058.57 \\
50 & 0.72 & 71.82 & 77.72 & 257.60 & 1027.43 \\
100 & 0.82 & 71.10 & 77.03 & 254.69 & 1017.76 \\
200 & 0.89 & 70.68 & 76.38 & 252.45 & 1010.39 \\
500 & 0.95 & 69.75 & 76.49 & 250.78 & 1004.62 \\
1000 & 0.97 & 69.92 & 75.98 & 250.05 & 1002.40 \\
\hline
\end{tabular}

\section{References}

[1] Bellman R. E., and Zadeh, L. A., (1970), Decision-making in a fuzzy environment, Management science, 17, 141-164.

[2] Carlsson, C. and Korhnen, (1986), A parametric approach to fuzzy linear programming, Fuzzy sets and systems, 20, 17-20.

[3] Giri B.C., Pal S., Goswami A. and Chudhuri K.S., (1996), An inventory model for deteriorating items with stock-dependent demand rate, European journal of Operational Research, 95, 604610.

\section{Concluding Remark}

In this paper, a real life inventory problem in fuzzy environment has been proposed and presented its situations along with a sensitivity analysis approach. Here exponential membership function is considered to represent the nature of variations in inventory costs. Objective goal and budget are represented by linear membership functions. Depending on the earlier experience or past values of these parameters, the other types of membership functions such as piecewise linear, cubical parabolic, L-R fuzzy number, etc. can be considered to construct the membership functions for the above inventory parameters and then the model can be easily solved by the present method. The proposed methodology can be extended to other inventory problems including the ones with two storage, multi-objective, etc.

[4] Mandal, M, T. K, Roy and Maiti, M., (1998), A Fuzzy inventory model of deteriorating items with stock dependent demand under limited storage space, Operations Research 35 [4], 323-337.

[5] Mandal, S. and Maiti, M., (2002), Multi-item fuzzy EOQ models, using genetic algorithm, Computers and Industrial Engineering, 44, 105-117.

[6] Tanaka, H., Okuda, T. and Asai, K. (1974), On fuzzy mathematical programming, Journal of Cybernetics, 3 (4), 37-46.

[7] Zimmermann, H.J., (1978), Fuzzy programming and linear programming with several objective function, Fuzzy Set and Systems 1, 45-55.

[8] Pattnaik, Monalisha, (2012), An EOQ model for perishable items with constant demand and instant deterioration, Decision, 39 [1].

[9] Pattnaik, Monalisha, (2013), Optimal decision in fuzzy NLP EOQ model for a single item and dynamic setup cost with space constraint, World Journal of Modelling and Simulation, 9 [1],7480 . 